OPEN ACCESS

Edited by:

Stephan Zipfel,

University of Tubingen, Germany

Reviewed by:

Florian Junne,

Universität Tübingen, Germany

Nicola Luigi Bragazzi,

Università di Genova, Italy

*Correspondence:

Chiara Conti

cconti@unich.it

Specialty section: This article was submitted to

Psychopathology,

a section of the journal

Frontiers in Psychology

Received: 15 June 2018 Accepted: 31 December 2018

Published: 17 January 2019

Citation:

Lanzara R, Scipioni M and Conti C (2019) A Clinical-Psychological

Perspective on Somatization Among Immigrants: A Systematic Review.

Front. Psychol. 9:2792.

doi: 10.3389/fpsyg.2018.02792

\section{A Clinical-Psychological Perspective on Somatization Among Immigrants: A Systematic Review}

\author{
Roberta Lanzara, Mattia Scipioni and Chiara Conti* \\ Department of Psychological, Health and Territorial Sciences, Università degli Studi G. d'Annunzio Chieti e Pescara, Chieti, \\ Italy
}

Background: Somatic and psychopathological conditions (e.g., anxiety, depression, post-traumatic stress disorder, and somatization) are frequent among immigrants belonging to various ethnic groups. Worldwide findings on the epidemiology regarding specific mental conditions still vary with respect to different migration samples and migration contexts. This inconsistency also holds true in the incidence of somatization among migrants. We carried out a systematic review analyzing the relationship between migration and somatization by providing a qualitative data synthesis of original research articles on the topic.

Methods: According to PRISMA guidelines, we conducted a systematic search of the literature on PubMed, Scopus, ISI Web of Science, PsycINFO, Google Scholar, and ScienceDirect. The articles were selected using multiple combinations of relevant search terms (e.g., defined somatization and related disorders, and migration status). Each database was searched systematically from January 2000 to December 2017.

Results: The initial search identified 338 records, of which 42 research reports met the predefined inclusion criteria and were analyzed. Most studies $(n=38$; 90\%) were cross-sectional. The main findings of this study are that migrants with somatization exhibited more psychological distress, had an increased perceived need for healthcare service utilization, and reported more post-migration living difficulties and/or post-traumatic stress disorder than those without somatization. It was also found that specific individual features mediate the association between somatization and migration. The prevalence and correlates of somatization were found to vary across the immigrant groups, depending on cultural variation in reasons for migration, stress exposure, explanatory models of illness, coping, and other individual variables.

Conclusion: Somatization is a challenge for health professionals due to its vague nature. In this regard, clinical management of immigrant patients should include further efforts to address emotional distress, with special attention to social, cultural, and linguistic differences.

\section{Keywords: immigrants, immigration, somatization, somatic symptoms, traumatic experience}

\section{INTRODUCTION}

Migration can be defined as "a process of moving, either across an international border, or within a State. Encompassing any kind of movement of people, whatever its length, composition and causes; it includes refugees, displaced persons, uprooted people, and economic migrants" (Perruchoud, 2004). During the period from 2000 to 2017, the total number of international 
migrants increased from 173 to 258 million persons, an increase of 85 million (49\%); 65 million of the world's internal and international migrants are forcibly displaced today (United Nations Population Division Department of Economic Social Affairs, 2009, 2017). Most migration processes may be conceptualized as a series of mainly stressful life events, each with the cumulative capacity to increase the risk for a broad range of mental health problems (Carta et al., 2005). Immigrants are often subjected to specific risk factors related mainly to exposure to stressful and traumatizing experiences (Shiroma and Alarcon, 2011; Rohlof et al., 2014), including the migrant status itself and, further, the associated acculturative stress and adaptation process to a new culture, racial discrimination, urban violence, abuse by law enforcement officers, and forced removal or separation from their families (Bermejo et al., 2010; Bragazzi et al., 2014). Several studies indicate that the incidence of psychological distress (Carta et al., 2005), post-traumatic stress disorder (PTSD) (Silove et al., 1998), major depressive disorder (Beirens and Fontaine, 2011), and somatization in diverse ethnic immigrant groups has increased all over the world (Haller et al., 2015).

Somatization is a complicated concept to define. Straddling the interface between physical and psychological ill health, it is often viewed from a range of different perspectives (Gureje et al., 1997). One finds in the literature definitions emphasizing the presence of multiple complaints in diverse areas of the body (Mai and Merkey, 1980; Escobar et al., 1989), formulations in which fear of having a serious physical disorder in the absence of supporting physiologic impairments is stressed (Barsky and Klerman, 1983), and others in which physical complaints are seen as manifestations of hidden psychiatric morbidity (Bridges and Goldberg, 1987). The concept of somatization has its origins in the work of Freud (Breuer and Freud, 1893-1895), who proposed the idea of conversion as a main defense mechanism. Following that, Alexander (Alexander, 1950) brought the notion of emotional equivalents, also proposed by Freud, into the concept of vegetative neurosis and psychosomatic diseases. Of late, somatization is often regarded as "a tendency to experience and communicate somatic distress in response to psychosocial stress and to seek medical help for it" (Lipowski, 1988). Somatization is most often associated with depressive and anxiety disorders (Simon et al., 1999; Haller et al., 2015); its persistent form is especially costly and difficult to prevent and manage. It thus poses major medical, social, and economic challenges (Lipowski, 1988).

Physical manifestations implicated in somatization can be aligned across a spectrum of numerosity, severity, and functional impairment, extending from just one or a few transient symptoms at one end, to having multiple severe symptoms for a long period of time and therefore meeting diagnostic criteria for somatoform disorder (SD) according to the Diagnostic and Statistical Manual of Mental Disorders (4th ed.; DSM-IV) (American Psychiatric Association, 1994) or somatic symptom disorder (SSD) according to the 5th edition (DSM-5) (American Psychiatric Association, 2013), at the other end (Jackson and Kroenke, 2008).

In the most recently released DSM-5, the conceptualization of somatization and what was previously termed somatoform disorder has changed substantially compared with previous diagnostic systems. This reflects an effort to overcome the limitations of the DSM-IV definition, which was organized centrally around the concept of medically unexplained symptoms (MUS). The current diagnostic criteria for SSD requires the presence of somatic symptoms combined with a substantial impact of these symptoms on thoughts, emotions, and behaviors (Carta et al., 2005), by emphasizing the extent to which feelings concerning their somatic symptoms are disproportionate or excessive. Somatization is a psychological dimension common to all people; it manifests in response to psychosocial stress brought about by life events and situations that are personally stressful to the individual (Lipowski, 1988). It has been strongly associated with the migrant status itself, as a coping or adapting mechanism extremely disadvantageous for health (Castillo et al., 1995; Escobar, 1995; Kirmayer and Sartorius, 2007; Radl-Karimi et al., 2018).

There are major differences in somatization among immigrants according to the moderating effects of psychosocial features such as their ethnic, cultural and religious background; exposure to trauma; reasons for migration; and other individual differences (Kirmayer and Young, 1998). These characteristics also differentially affect illness perception, communication of symptoms, and help-seeking behavior. Clinical-psychological assessment and treatment of somatization thus can be particularly challenging in multicultural contexts (Carta et al., 2005), imposing a considerable economic burden on health services.

To our knowledge, systematic attempts to investigate the frequency and clinical-psychological correlates of somatization in a wide spectrum of migrant populations have thus far not been undertaken. To address these gaps, we carried out a systematic review examining the prevalence, clinical manifestation, etiology, and treatment of somatization in individuals with migratory background, by providing a qualitative data synthesis of the studies. The inclusion of papers in this review was extended to those investigating somatization as the somatic clinical presentation of psychological distress, high levels of somatic preoccupation, MUS, or mental disorder (according to DSM-IV or DSM-5).

Based on the extant literature, we expected that: (1) somatization would be significantly associated with migration because of the supposed high exposure to stressful experiences in individuals with migratory backgrounds; and (2) the prevalence and correlates of somatization would vary across immigrant groups, depending on cultural variations in reasons for migration, trauma exposure, coping, and other individual variables.

\section{MATERIALS AND METHODS Eligibility Criteria}

Eligible articles included all English language papers published in peer-reviewed journals from January 2000 to December 2017, reporting data on the presence of somatization in first-generation immigrants. When a title or abstract seemed to describe a study eligible for inclusion, the full text was examined to consider 
its relevance according to the inclusion criteria. Reviews, metaanalyses, commentaries, letters to the editor, books or book chapters, abstracts, and clearly irrelevant papers were excluded. Since somatization is particularly difficult to operationalize, we also excluded articles published before 2000 for a greater homogeneity on the meaning of somatization.

The included studies had to:

(1) examine a population of first-generation adult immigrants. Immigrants are defined as foreign born people who have moved to another country for the purpose of settlement (Perruchoud and Redpath-Cross, 2011). This definition includes economic migrants, temporary foreign workers, foreign students, documented and undocumented migrants, refugees, and asylum seekers;

(2) investigate somatization defined as somatic presentation of psychological distress, or MUS, or high levels of somatic preoccupation and worry about illness, or the clinical presentation of psychiatric disorder according to DSM-IV or DSM-5;

(3) use questionnaires, subscales, semi-structured interviews, or DSM criteria for assessing somatization.

\section{Information Sources and Searches}

This systematic review was conducted according to the Preferred Reporting Items for Systematic Reviews and Meta-Analyses (PRISMA) guidelines (Liberati et al., 2009). PubMed, Scopus, ScienceDirect, ISI Web of Science, PsycINFO, and Google Scholar databases were systematically searched in November 2017 using the following Boolean string: ("immigrant*" OR "migrant*" OR "immigration" OR "migration" OR "refugee*” OR "asylum seeker*”) AND ("somatization" OR "somatizer*” OR "medically unexplained symptom*” OR "functional disease" OR "functional symptom*" OR "somatic symptom* disorder" OR "illness anxiety disorder" OR "conversion disorder" OR "functional neurological symptom*” OR "psychological factors affecting med*" OR "factitious disorder") [All Fields]. Each database was systematically searched for articles from January 2000 to December 2017. After performing the initial search, duplicates were identified and discarded. Titles and abstracts were screened and, for reports thus identified as potentially relevant, full texts were checked for eligibility. Studies were discarded where the full text was unavailable. Searching and determining the eligibility of target responses were carried out independently by the three investigators.

\section{Selection of Articles and Data Extraction}

Two of the authors (R.L., M.S.) performed the initial data extraction by removing duplicates and all the articles that appeared clearly irrelevant based on the salience of the title and after reading the specific abstract. The full texts of the remaining studies were independently assessed for eligibility by all authors. After a full-text evaluation of the potentially relevant studies, the three authors reached a consensus regarding eligibility and excluded all the research articles that not meet the inclusion criteria.

\section{Analysis and Data Synthesis}

The methods described here fulfilled the PRISMA guidelines (Liberati et al., 2009), as a meta-analysis was deemed inappropriate due to the heterogeneity of the examined study designs. To assess the risk of bias, and working independently; the reviewers each determined the adequacy of the methodology in terms of reliability. Within the sample selected for review, studies were categorized by summarizing and comparing significant information and specifying the measures of the assessed variables for each (see Table $\mathbf{1}$ for a detailed description of the reviewed studies).

\section{RESULTS}

The search of electronic databases initially yielded $N=338$ citations, as reported in the PRISMA flowchart (Figure 1). After removing the duplicates, $N=217$ records remained. Of these, $n=139$ citations were eliminated as they were reviews, metaanalyses, commentaries, letters to the editor, books or book chapters, abstracts, or non-English language papers, or because they did not meet the inclusion criteria. Of the 78 full text articles assessed for eligibility, $n=36$ studies were excluded by focusing both on inclusion and exclusion criteria. Ultimately, $N=42$ studies were selected for inclusion in the systematic review (see Table 1 for a detailed description of the reviewed studies).

The reviewed studies were published between 2000 and 2017. These 42 papers reported the results of 38 cross-sectional analyses and four longitudinal analyses. In this section, the studies are mainly grouped and described based on the characteristics of migrant populations at risk for somatization.

\section{Measurement and Assessment of Somatization}

Table 1 summarizes the measurement and assessment of somatization in the included studies. Twenty-nine records used self-report questionnaires; of these, 22 specified in which language the questionnaires were administered and whether the scales were adapted to the language of the participants (see Table 1). Thirteen articles (Mak and Zane, 2004; Nickel et al., 2006; Cwikel et al., 2008; Sachs et al., 2008; Shiroma and Alarcon, 2011; David et al., 2012; Heredia Montesinos et al., 2012; Mölsä et al., 2014, 2017; Rask et al., 2015, 2016; Spiller et al., 2016; Choi et al., 2017) used the Symptom Checklist-90-R (SCL90-R) Somatization subscale (Derogatis, 1977). The SCL-90-R consists of nine subscales aimed at measuring psychopathology, including somatization. Seven studies (Aragona et al., 2005, 2008, 2010, 2011, 2012, 2013; Deisenhammer et al., 2012) assessed somatization using the Bradford Somatic Inventory (BSI-21) (Mumford et al., 1991), a widely validated self-assessment questionnaire specifically designed for transcultural research and formerly used to assess somatization among groups of primary care immigrants. The Patient Health Questionnaire-15 (PHQ-15) (Dreher et al., 2017; Mendoza et al., 2017; Morawa et al., 2017) and the Hopkins Symptom Checklist-37 (HSCL-37) (Breuer and Freud, 1893-1895; Alexander, 1950; Derogatis, 1977; Mai and Merkey, 1980; Barsky and Klerman, 1983; Bridges and Goldberg, 


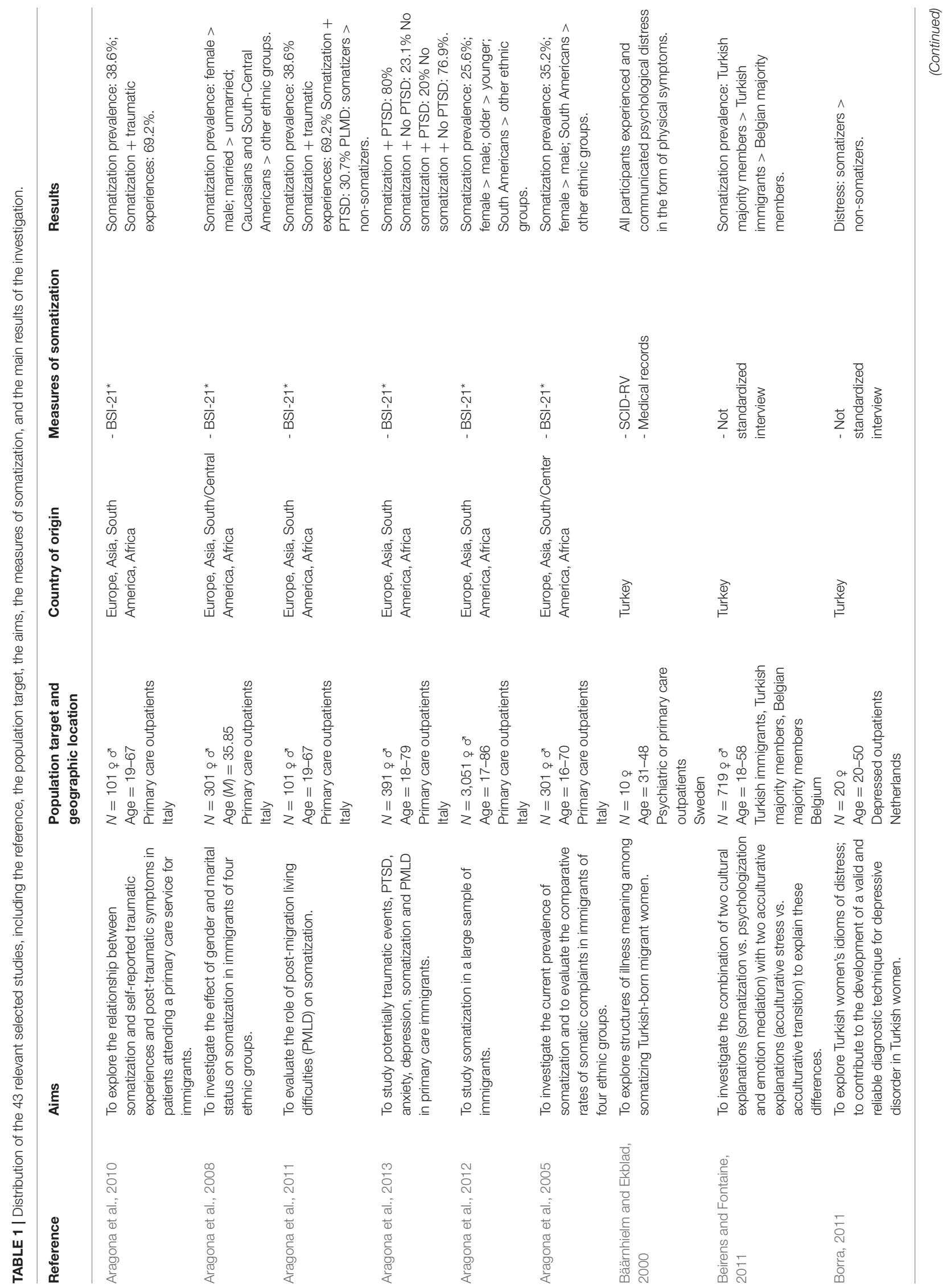




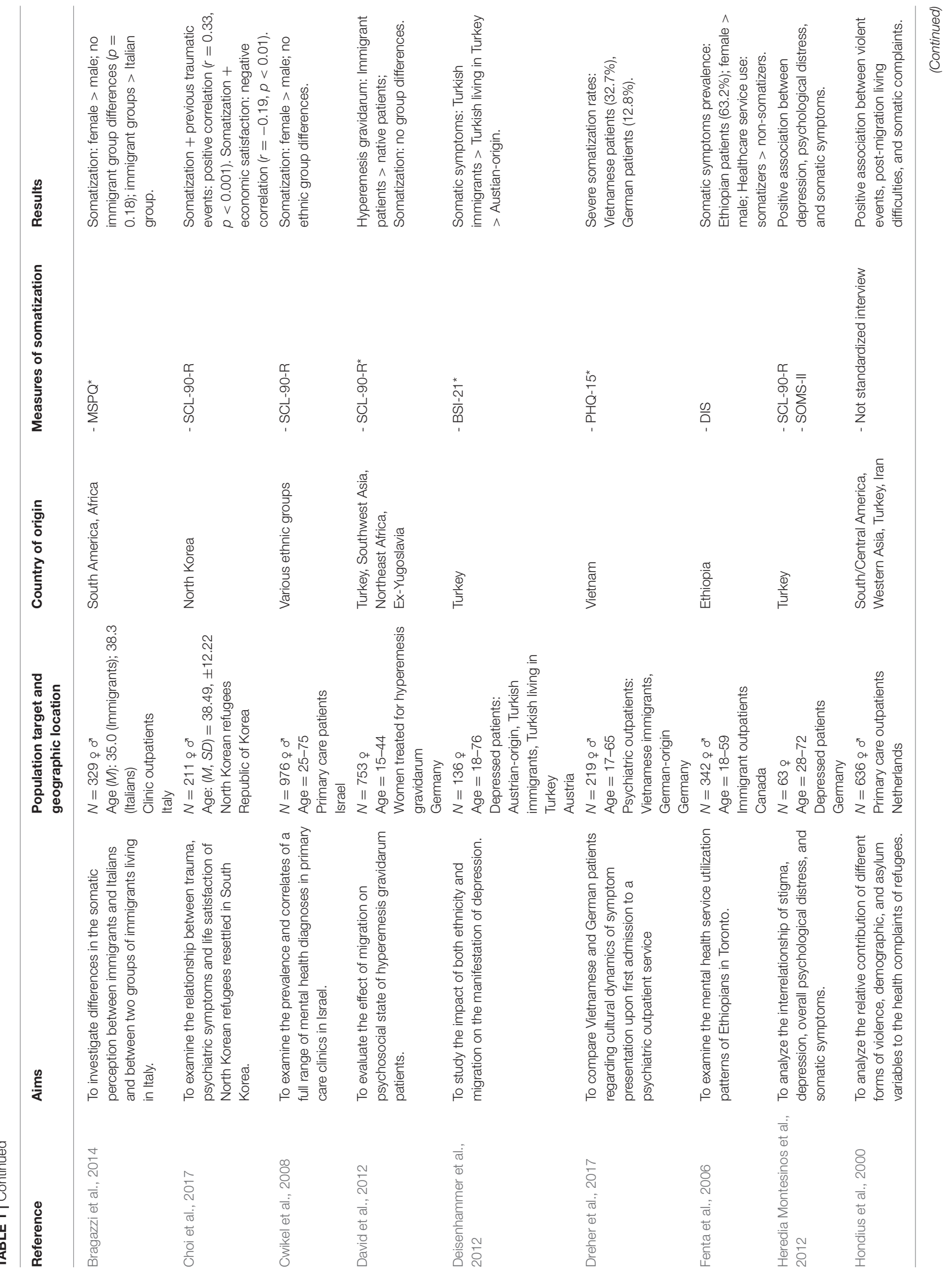




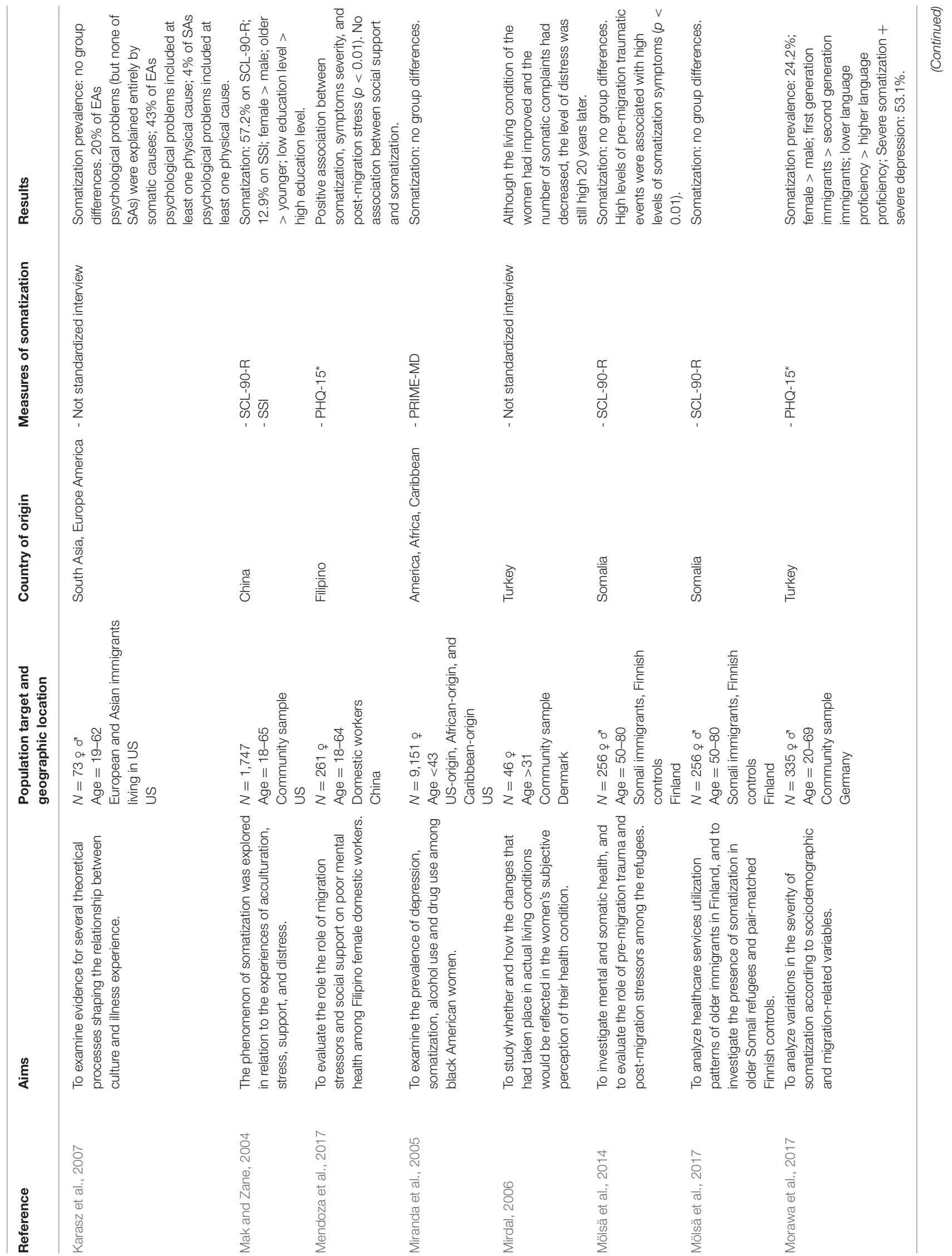



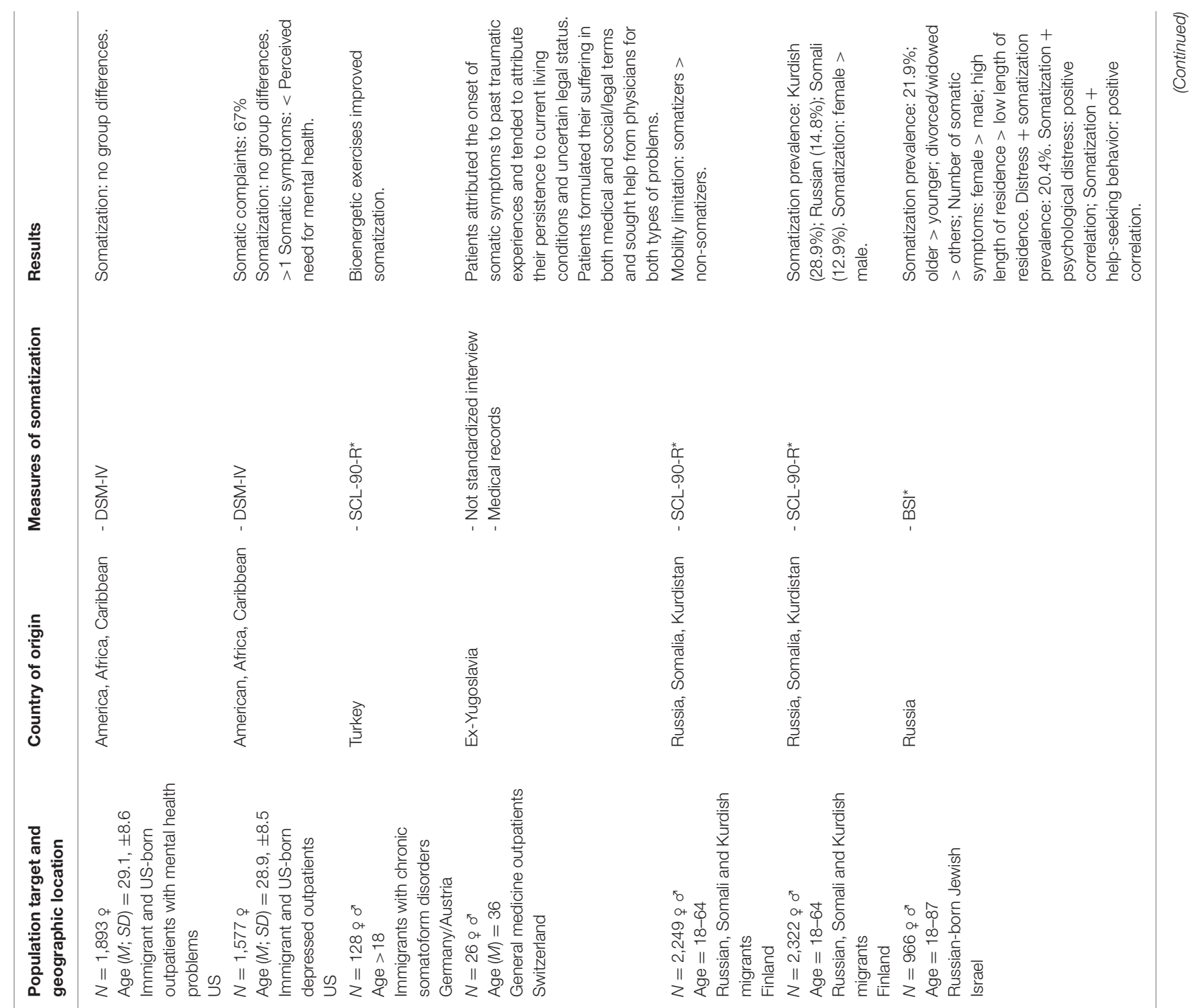

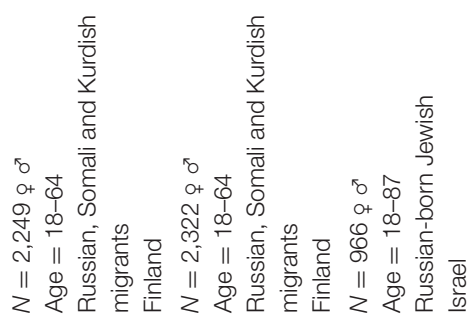
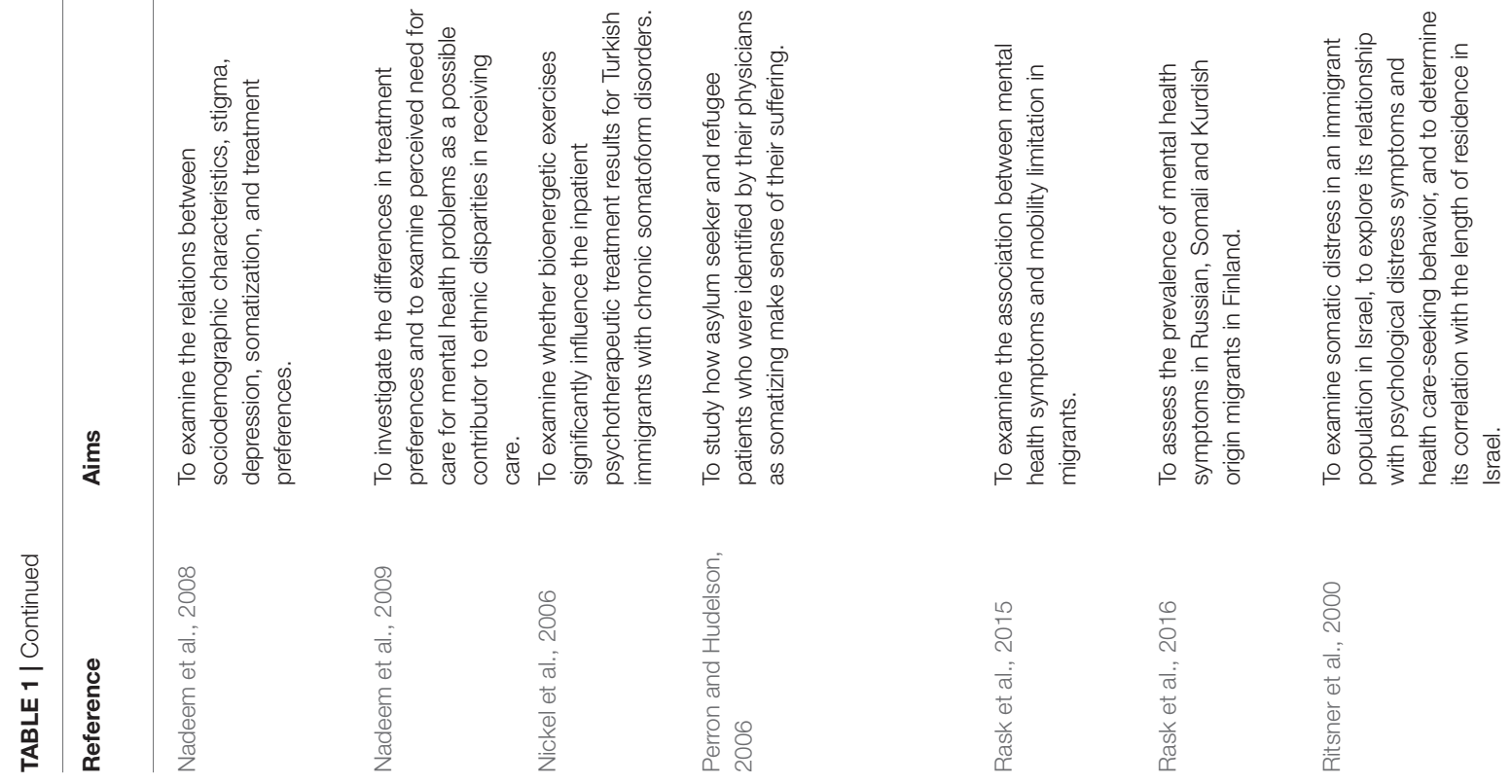

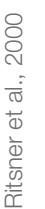




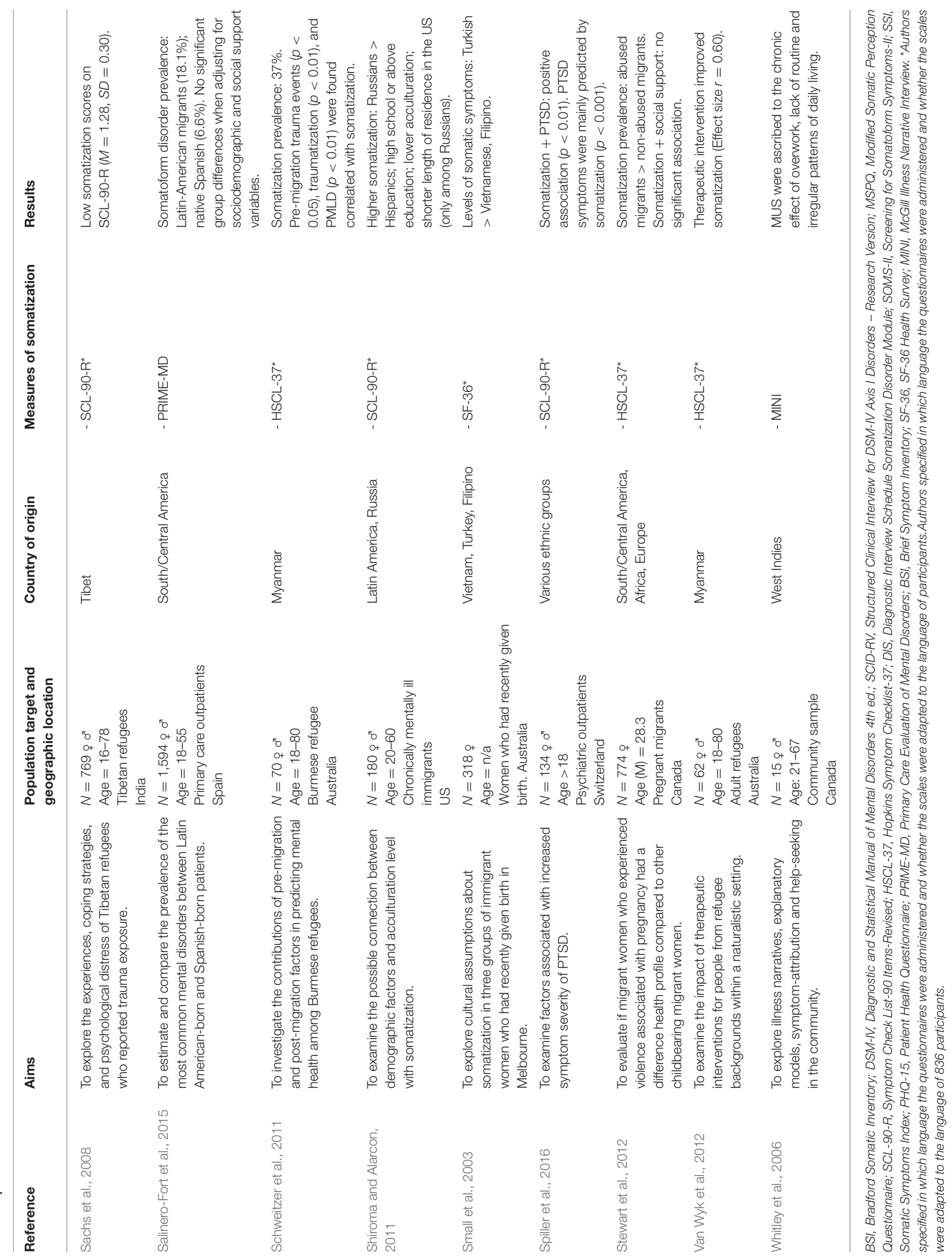


1987; Lipowski, 1988; Escobar et al., 1989; Mumford et al., 1991; American Psychiatric Association, 1994, 2013; Castillo et al., 1995; Escobar, 1995; Gureje et al., 1997; Kirmayer and Young, 1998; Silove et al., 1998; Simon et al., 1999; Mak and Zane, 2004; Aragona et al., 2005, 2008, 2010, 2011, 2012, 2013; Nickel et al., 2006; Kirmayer and Sartorius, 2007; Cwikel et al., 2008; Jackson and Kroenke, 2008; Sachs et al., 2008; Liberati et al., 2009; Bermejo et al., 2010; Beirens and Fontaine, 2011; Perruchoud and Redpath-Cross, 2011; Schweitzer et al., 2011; Shiroma and Alarcon, 2011; David et al., 2012; Deisenhammer et al., 2012; Heredia Montesinos et al., 2012; Stewart et al., 2012; Van Wyk et al., 2012; Bragazzi et al., 2014; Mölsä et al., 2014, 2017; Rohlof et al., 2014; Haller et al., 2015; Rask et al., 2015, 2016; Spiller et al., 2016; Choi et al., 2017; Dreher et al., 2017; Mendoza et al., 2017; Morawa et al., 2017; Radl-Karimi et al., 2018) were each used in three records. The PHQ-15 consists of four subscales: Somatoform Disorder, Depressive Disorder, Panic Disorder, and Functioning of the Patient. The HSCL-37 measures symptoms along three subscales: Anxiety, Depression, and Somatization (Derogatis et al., 1974). The other questionnaires, i.e., Screening for Somatoform SymptomsII (SOMS-II) (Heredia Montesinos et al., 2012), the Somatic Symptoms Index (SSI) (Mak and Zane, 2004), the SF-36 Health Survey (SF-36) (Small et al., 2003), the Modified Somatic Perception Questionnaire (MSPQ) (Bragazzi et al., 2014), and the Brief Symptom Inventory (BSI) somatization subscale (Ritsner et al., 2000) were used in one article each. The SOMS-II evaluates somatization disorder according to DSM-IV (Rief et al., 1997). The SSI measures somatization disorder and is based on the DSM classification (Escobar et al., 1989). The SF-36 provides a measure of physical, mental, and social functioning (Ware and Sherbourne, 1992). The MSPQ is a scale used to measure somatization and to investigate body perception and physiologic functions (Main, 1983). The BSI was developed from the SCL-90$\mathrm{R}$; its Somatization subscale measures the distress arising from perceptions of bodily dysfunction (Derogatis and Spencer, 1982). Four studies (Bäärnhielm and Ekblad, 2000; Miranda et al., 2005; Fenta et al., 2006; Salinero-Fort et al., 2015) assessed somatization administering standardized semi-structured interviews based on the DSM-IV classification, i.e., Structured Clinical Interview for DSM-IV Axis I Disorders - Research Version (SCID-RV) (Bäärnhielm and Ekblad, 2000), Diagnostic Interview Schedule (DIS) Somatization Disorder Module (Fenta et al., 2006), and Primary Care Evaluation of Mental Disorders (PRIMEMD) (Miranda et al., 2005; Salinero-Fort et al., 2015). Each aims to give a measure of common mental health problems, including somatoform disorders (Swartz et al., 1986; Spitzer et al., 1994; First et al., 1997). Whitley et al. (Whitley et al., 2006) administered the McGill Illness Narrative Interview (MINI) (Groleau and Kirmayer, 2004). The MINI has been used in crosscultural research in many cultures and contexts to explore diverse health issues and conditions, including MUS. Six records assessed somatization using unstandardized semi-structured interviews (Hondius et al., 2000; Mirdal, 2006; Perron and Hudelson, 2006; Karasz et al., 2007; Beirens and Fontaine, 2011; Borra, 2011) mainly focused on: MUS (Perron and Hudelson, 2006; Karasz et al., 2007), emotional distress associated with physical

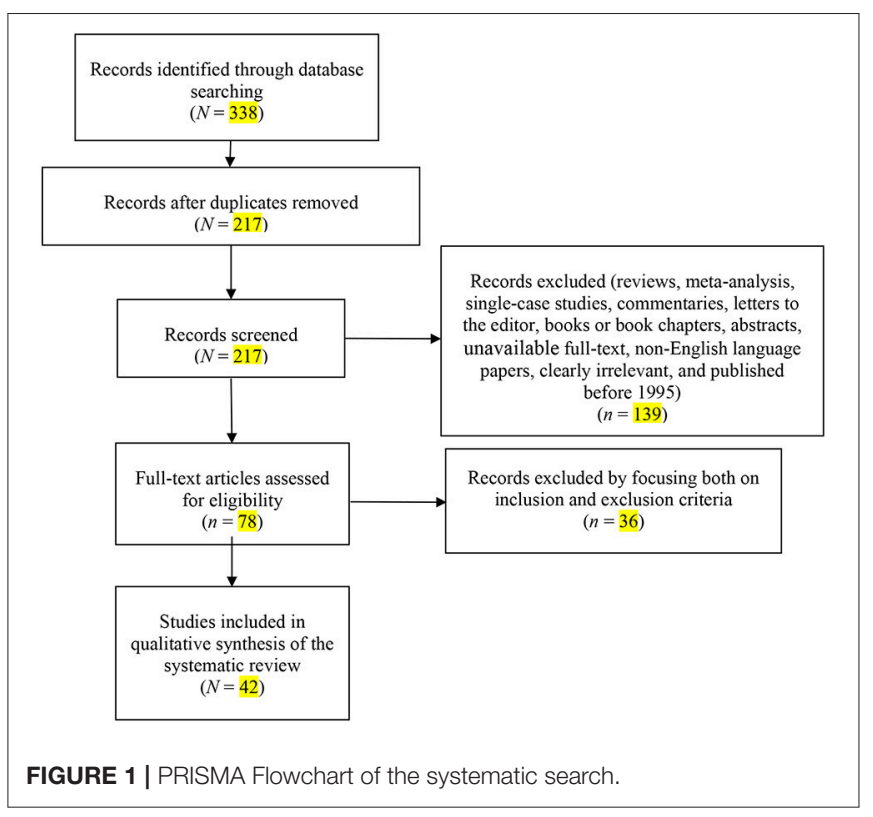

symptoms (Beirens and Fontaine, 2011), and somatic complaints (Hondius et al., 2000; Mirdal, 2006; Borra, 2011). Finally, in two studies conducted by Nadeem et al. (Nadeem et al., 2008, 2009), participants were classified as somatizers when they reported six or more DSM-IV symptoms of somatization disorder.

\section{International Migrants Compared to Host Country Natives}

Eight studies did not find significant differences in levels of somatization between migrant and local populations. In a study undertaken to assess the prevalence of mental disorders in 1,594 outpatients seen in primary care, Salinero-Fort et al. (2015) found that the prevalence of somatoform disorders was significantly higher $(p<0.001)$ among Latin American immigrants $(18.1 \%)$ than in Spanish native-born outpatients (6.6\%); however, the association became not statistically significant after adjusting for sociodemographic variables. Miranda et al. (2005) compared 9,151 low-income African-born, Caribbean-born, and US nativeborn black women on rates of somatic symptoms. Rates of somatization were similar across the three groups (3.2, 3.3, and $2.8 \%$, respectively). In two studies, Nadeem et al. $(2008,2009)$ recruited low-income immigrant and US-born women with perceived mental health problems. In both studies the groups did not differ significantly in somatization rates. Two studies conducted in Finland (Mölsä et al., 2014, 2017) investigated the presence of somatization in older Somali refugees and pairmatched Finnish controls; no group differences were found. In a comparative study, David et al. (2012) investigated group differences in somatization using a sample of 753 immigrant and German native-born women treated for hyperemesis gravidarum. Although the number of immigrant women treated for hyperemesis gravidarum was higher compared to the resident population, both groups showed high levels of somatization. Finally, in a study that compared 576 immigrants of different 
ethnic groups and 400 Israeli native-born patients accessing primary care clinics (Mirdal, 2006), no significant group differences in rates of somatization were found.

Somatization was found to be significantly prevalent in immigrants in only four studies that compared samples of immigrants with the host country's natives (Beirens and Fontaine, 2011; Deisenhammer et al., 2012; Bragazzi et al., 2014; Dreher et al., 2017). An Italian study (Bragazzi et al., 2014) investigated the differences in somatic perception between a group of 143 immigrant outpatients from South America and Africa vs. a control group of 186 Italian outpatients. After adjusting for gender and age differences, the immigrant group showed significantly higher mean scores of somatic disturbances than the control group $(p<0.01)$. In a comparative study involving Vietnamese immigrant and native German outpatients (Dreher et al., 2017), 32\% of Vietnamese patients were classified as suffering from severe somatic symptoms, while only $12.8 \%$ of the German patients reported severe somatic symptoms ( $p$ $<0.001$ ). Deisenhammer et al. (Deisenhammer et al., 2012) compared 40 Turkish immigrant women, 55 Turkish women residing in Turkey, and 41 Austrian native-born women. Results showed that Turkish immigrants had the highest prevalence of somatic symptoms, though not significantly higher than Turkish persons living in Turkey. Beirens and Fontaine (2011), who investigated somatization-related complaint differences between 144 Turkish immigrants, 222 Turkish living in Turkey, and 353 Belgians native-born, found that Turkish groups living in Turkey reported a higher tendency to somatize, followed by Turkish immigrants and Belgians.

\section{Sociodemographic and Cultural Predictors of Somatization}

Thirteen studies investigated the relationship between specific sociodemographic characteristics and somatization in immigrants. Reports showed that being female (Ritsner et al., 2000; Mak and Zane, 2004; Aragona et al., 2005, 2008, 2012; Fenta et al., 2006; Cwikel et al., 2008; Bragazzi et al., 2014; Rask et al., 2016; Morawa et al., 2017), older (Ritsner et al., 2000; Mak and Zane, 2004; Mölsä et al., 2014, 2017), and having low language proficiency (Dreher et al., 2017; Morawa et al., 2017) are significant and common sociodemographic risk factors for somatization among immigrants.

Conflicting results have been found on marital status (Ritsner et al., 2000; Aragona et al., 2008), education level (Aragona et al., 2008; Shiroma and Alarcon, 2011), acculturation level (Mak and Zane, 2004; Shiroma and Alarcon, 2011), length of residence (Ritsner et al., 2000; Mak and Zane, 2004; Shiroma and Alarcon, 2011; Aragona et al., 2012), and economic satisfaction (Mirdal, 2006; Choi et al., 2017), relative to somatization. The effect of education level on somatization was investigated in an American study involving 1,747 Chinese immigrants (Mak and Zane, 2004). The authors found that the experience of somatization was more prevalent among individuals with less than college education. In contrast, in a study involving 180 Russian and Latino immigrants in the US (Shiroma and Alarcon, 2011), high school or above levels of education were found to be significantly associated with higher somatization. The effect of marital status on somatization was investigated in an Italian study involving 301 outpatients of various ethnic groups (Aragona et al., 2008). The authors showed a significantly increased risk for somatization among Caucasian-married subjects $(p=0.035)$. Ritsner et al. (2000) examined somatic distress and its correlation with specific demographic characteristics in 966 Russian-born Jews who had migrated to Israel. Overall, the prevalence of somatization was 21.9\%; divorced and widowed respondents, compared to married and single respondents, were more likely to meet the criteria for somatization. The authors also found that longer length of residence in the host country was associated with higher levels of somatization symptoms $(p<0.0001)$. A cross-sectional study (Shiroma and Alarcon, 2011), involving Russian and Hispanic immigrants living in the US, found conflicting results. In the univariate and multivariate analyses, shorter length of stay in the US was significantly related to somatization (though only among Russians; $p<0.001)$ and higher somatization scores were significantly related to lower acculturation $(p<0.001)$ within both groups. Conversely, in a study of 1,747 Chinese Americans in Los Angeles County, length of residence in the host country and acculuration were not related to somatization (Mak and Zane, 2004). In this investigation, the prevalence of somatization for the total sample was $12.9 \%$. Aragona et al. (2012) assessed differences in somatization among Europeans, Asians, South Americans, and Africans living in poor social conditions. Among the 3,051 recruited outpatients, 25.6\% were somatizers, but there were no significant differences in the duration of permanence in Italy and immigrant regular/irregular status. Focusing on economic satisfaction, a follow-up study conducted in the US (Mirdal, 2006) showed that, although living conditions of subjects had improved (i.e., economic independence and social improvement) during the last 20 years, and the number of somatic complaints had decreased, levels of distress were still high. In a study examining the relationship between somatization and life satisfaction of North Korean refugees resettled in South Korea (Choi et al., 2017) somatization was found to be related only to the economic satisfaction domain $(r=-0.19, p<0.01)$.

Six of the examined studies compared immigrants of different ethnic groups and considered the associations between ethnicity or other sociodemographic factors and somatization.(Aragona et al., 2005) evaluated the prevalence of somatization in a sample of 301 immigrants of four ethnic groups (Caucasian, Asian, South-Central American, and African) attending a primary care service in Italy. The prevalence of somatization in the total sample was found to be $35.2 \%$. Somatization was significantly higher in South-Central Americans than in other ethnic groups $(p=0.012)$. In a subsequent study involving the same sample (Aragona et al., 2008), subgroup analysis of the ethnic groups showed a significantly increased risk for somatization only for Caucasian $(p=0.001)$ and South-Central American $(p=$ 0.003 ) women and Caucasian married persons $(p=0.035)$. In another multicultural study conducted in Italy, Aragona et al. (2012) assessed the differences in somatization among immigrant outpatients living in poor social conditions. Among the 3,051 recruited participants, $25.6 \%$ were somatizers, the greatest proportion of whom were from South America (30.1\%), followed 
by Europeans (23.2\%), Africans (21.2\%), and Asians (16.3\%). Specifically, the authors found that somatization occurred more frequently in Peruvians (32.9\%). Small et al. (2003) compared 107 Turkish, 104 Vietnamese, and 107 Filipino women who had recently given birth in Australia. Results showed that Turkish women were the most likely of the three groups to report high levels of somatic symptoms, followed by Vietnamese and Filipino women. In two studies, Rask et al. $(2015,2016)$ assessed and compared the prevalence of mental health symptoms among Russian, Somali, and Kurdish immigrants in Finland. The prevalence of somatization was $14.8 \%$ for Russians, $12.9 \%$ for Somalians, and $28.9 \%$ for Kurds (Rask et al., 2016). The authors also reported that somatization increased the odds for mobility limitation within all migrant groups (Russians OR 4.29; Somalis OR 18.83; Kurds OR 3.53) (Rask et al., 2015).

\section{Clinical Psychological Features of Immigrants at Somatization Risk}

To date, ten investigations have examined the association between somatization, general psychological distress, and other vulnerability or protective psychological factors in individuals with migratory backgrounds. Three studies found positive associations between psychological distress and a wide range of somatic complaints in depressed patients (Mak and Zane, 2004; Borra, 2011; Heredia Montesinos et al., 2012). Borra (2011) showed higher levels of psychological distress in Turkish depressed women living in the Netherlands who reported somatic symptoms than Turkish depressed women without somatic symptoms. Heredia Montesinos et al. (2012) showed significant correlations between depression $(p<0.101)$, overall psychological distress $(p<0.001)$, and somatic symptoms in Turkish depressed women living in Germany. Mak and Zane (2004) found similar results in a sample of 333 Turkish immigrants in Germany, where $24.2 \%$ of the total sample exhibited severe levels of somatization. Among these somatizing persons, $53.1 \%$ also reported comorbid severe levels of depression $(r=0.74)$.

In a Swedish qualitative study, Bäärnhielm and Ekblad (2000) found that Turkish migrant participants $(N=10)$ experienced and communicated psychological distress in the form of physical symptoms, even when somatic diagnoses were present. Distress was communicated by concrete expressions about the body, emotions, and social and life situations. The participants' illness attribution patterns were mostly characterized by not verbalizing causal explanations, but rather links of coherence between health and various aspects of life. Ritsner et al. (2000) investigated the relationship between psychological distress and somatization in an immigrant population in Israel. The co-occurrence of these factors was $20.4 \%$. Somatization was positively correlated with the intensity of psychological distress $(p<0.001)$. Similar results were found in a study involving a representative community sample of Chinese Americans (Mak and Zane, 2004); it was reported that anxiety $(p<0.001)$, depression $(p<0.001)$, adverse lifetime events $(p<0.05)$, and social support $(p<0.05)$ were significantly related to somatization.
Focusing on perceived social support, in a recent study (Mendoza et al., 2017) that evaluated the role of migration stressors on poor mental health among Filipino female domestic workers in China $(N=261)$, Mendoza et al. (2017) applied hierarchical multiple regression analysis to test for direct and moderating effects of social networks on psychological distress. Post-migration stress was significantly and positively correlated with somatization symptoms $(p<0.001)$ and with somatization symptom severity $(p<0.01)$. Social network support from family was not associated with somatization, nor did it modify the association between stress and these symptoms. Social network support from friends, however, was positively associated with somatization and significantly moderated the relationship between stress and these symptoms $(p<0.01)$. Stewart et al. (2012), investigating a sample of pregnant immigrant women, found that although abused women were more likely to have inadequate social support and to report more depression, anxiety, somatization, and PTSD $(p<0.001)$, social support status did not affect somatization.

Two studies examined the effect of cultural differences on somatization in immigrants, taking into account specific clinicalpsychological features. A study that compared Turkish persons living in Belgium, Turkish living in Turkey, and Belgians native-born. Turkish majorities scored higher on all somatic factors, anxiety-sadness, and self-conscious emotions followed by Turkish immigrants and Belgian majorities (Beirens and Fontaine, 2011). Indeed, the authors found a mediation effect of anxiety-sadness and self-conscious factors on the differences in somatic factors only between Belgians and non-migrated Turkish persons (Beirens and Fontaine, 2011). Sachs et al. (2008) explored the experiences, coping strategies, and psychological distress of Tibetan refugees in India who reported trauma exposure. The authors used data on coping strategies and cognitive appraisal of experience severity to test the hypothesis that these mechanisms mediate psychological outcomes. Participants reported notably low psychological and somatic symptoms; thus, coping activity (primarily religious) and subjective appraisals of the severity of their experiences (i.e., social comparison) appeared to mitigate the psychological effects of trauma exposure.

Finally, only two studies sought to evaluate the effects of treatment interventions on somatization in immigrants. In a 6-week randomized prospective controlled trial aimed at examining whether bioenergetic exercises significantly influenced the inpatient psychotherapeutic treatment results for 128 Turkish immigrants with chronic somatoform disorders, this activity appeared to improve symptoms of somatization (Nickel et al., 2006). A longitudinal nonrandomized study (Van Wyk et al., 2012) examined the impact of therapeutic interventions of mental health conducted with the aim of facilitating adjustment and acculturation for adult Burmese refugees within a naturalistic setting in Australia. Over the course of the interventions, participants experienced a significant decrease in symptoms of PTSD, anxiety, depression, and somatization $(r=$ $0.60)$. 


\section{Somatization and Health Behavior}

Six studies explored the associations between somatization and variations in perceptions of health, service utilization patterns, and treatment preferences in migrant populations. Karasz et al. (2007) investigated cultural differences in illness experience using a sample of immigrants divided into two groups: European Americans $(n=36)$ and South Asians $(n=$ 35 ). The groups reported similar symptoms, but the organization of illness episodes and explanatory models associated with these episodes differed sharply. Twenty percent of all European American psychological illness problems (but none of South Asian problems) were explained entirely by physical or somatic causes. Moreover, 43\% of European American psychological problems included at least one physical cause, while only $4 \%$ of psychological problems in the South Asian group included at least one physical cause.

The health service utilization patterns of immigrants and refugees were analyzed by Fenta et al. (2006) in a sample of 342 Ethiopians residing in Canada. The authors found that $63.2 \%$ of the respondents had experienced one or more somatic symptom(s) in the previous 12 months. The number of somatic symptoms experienced was positively associated with increased rate of medical services utilization $(p<0.05)$ and with increased utilization of nonmedical services (e.g., religious leaders, traditional healers, and other non-health professionals; $p<0.001$ ). Ritsner et al. (2000) investigated the relationship between psychological distress and somatization symptoms and healthcare-seeking behavior. Somatization was positively correlated with self-reported poor health and with healthcareseeking behavior $(p<0.001)$. Additionally, Mak and Zane (2004) found that a significantly higher percentage of Chinese American somatizers rated their health as poor or fair, compared to non-somatizers $(p<0.0001)$ and reported seeking help from both traditional Chinese and Western medicine $(p<0.01)$. In two studies, Nadeem et al. $(2008,2009)$ compared lowincome immigrants with US-born women with acknowledged mental health problems to investigate the differences in treatment preferences and perceived need for care. In the first study, somatization was found to be positively associated with endorsing medication $(p<0.05)$ and faith $(p<0.05)$ as a helpful treatment, with no significant differences between ethnic groups (Nadeem et al., 2008). The subsequent study (Nadeem et al., 2009) involved 1,577 low-income immigrant and US-born women with depression and found that having multiple somatic symptoms increased the likelihood of endorsing perceived need for care compared with having few somatic symptoms $(p<$ 0.001), across all the ethnical groups.

\section{The Clinical Link Between Trauma and Somatization}

Immigrants frequently experience multiple traumatic events in pre-migration as well as post-migration life. Hondius et al. (2000), in a study aimed at estimating the contribution of different forms of violence to the health complaints of refugees, confirmed that high frequencies of torture events and substantial numbers of medical complaints were common among immigrants. Specifically, the authors found that refugees attributed their somatic and psychological complaints to torture (29\%) and to worries related to PMLD (40\%). A positive correlation between somatization and the number of previous traumatic events $(r=0.33, p<0.001)$ was also observed in North Korean refugees resettled in South Korea (Choi et al., 2017). Similarly, studies that compared mental and somatic health among 256 elderly Somali refugees and Finnish controls found that high levels of pre-migration traumatic events were associated with high levels of somatization symptoms $(p<0.01)$ (Mölsä et al., 2014, 2017).

Several studies have shown significant associations between somatization, traumatic events, PTSD and PMLD. Pre-migration traumatic experience and PTSD are both frequently observed in immigrant somatizers. Many studies (Aragona et al., 2010, 2011, 2013; Schweitzer et al., 2011; Mölsä et al., 2014) have found a comorbidity between PTSD and somatization, ranging from $30.7 \%$ to $80 \%$. Aragona et al. $(2010,2011,2013)$ identified a high prevalence of somatization in a sample of immigrants who had experienced traumatic events, in three studies undertaken in 2010, 2011, and 2013. The first study (Aragona et al., 2010) conducted on 101 immigrant outpatients attending a primary care service, found that the number of somatizers reporting at least one traumatic event $(69.2 \%)$ was significantly higher than that of non-somatizers (40.3\%). In the second study (Aragona et al., 2011), conducted on the same sample, the authors found that having PTSD was significantly more common in somatizers $(30.7 \%)$ than in non-somatizers $(6.4 \%)$. This study also reported that the number of somatizers having serious or very serious PMLD was significantly higher than that of non-somatizers $(p=0.016)$. Finally, the third study (Aragona et al., 2013), conducted on 391 immigrant outpatients, found that patients with PTSD had highest potentially traumatic events rates (49.95\%), PMLD rates (56.94\%), and somatization rates $(80 \%)$. Consistent with these findings, Schweitzer et al. (2011) investigated the contributions of pre-migration and postmigration factors in predicting mental health among Burmese refugees in Australia. In this study, a substantial proportion of participants reported PTSD (9\%) and somatization (37\%). Pre-migration trauma events $(p<0.05)$, traumatization $(p<$ $0.01)$, and PMLD $(p<0.01)$ were found to be correlated with somatization. Stewart et al. (2012) recruited 774 pregnant immigrant women to evaluate whether immigrant women who experienced violence associated with pregnancy had a different health profile compared to other childbearing immigrant women. The study showed that immigrant women who reported abuse associated with pregnancy $(7.6 \%)$ were more likely to have symptoms of somatization $(p<0.001)$ and PTSD $(p<0.001)$.

A positive correlation between somatization and the severity of PTSD symptoms is also reported. Spiller et al. (2016) conducted a cross-sectional study to examine the factors associated with increased symptom severity of PTSD in 134 severely traumatized refugees. Somatization was found to be significantly related to PTSD $(p<0.01)$, trauma exposure ( $p$ $<0.01)$, and PMLD $(p<0.01)$. Specifically, PTSD symptoms were mainly predicted by somatization $(p<0.001)$ and anger $(p<0.001)$. Interestingly, only a cross-sectional study (Sachs 
et al., 2008) involving 769 Tibetan refugees found that levels of somatization were extremely low, despite the high prevalence of potentially traumatizing events. The authors observed that coping activity appeared to mediate the effects of trauma exposure on psychological distress $\left[F_{(2,763)}=17.96, p<0.001\right.$, $\left.R^{2}=0.02\right]$.

Finally, two studies focused on the illness narratives of immigrants suffering from somatic, emotional or MUS with the aim of exploring how immigrants made sense of their suffering. A Canadian study (Whitley et al., 2006) highlighted that West Indian immigrants ascribed their MUS almost exclusively to the chronic effect of post-migratory factors (overwork, lack of routin,e and irregular patterns of daily living). By contrast, a Swiss study (Perron and Hudelson, 2006) showed that Yugoslav asylum seekers attributed the onset of somatic symptoms to past traumatic experiences such as war, flight, and loss of loved ones, and talked about current difficult life conditions (financial worries, concerns about their children, uncertainty about the future, fear of expulsion, and lack of social support) as perpetuating their symptoms and posing barriers to improvement.

\section{DISCUSSION}

The present study aimed to systematically investigate published original research reports, evaluating the emerging clinical links between migration and somatization by providing a qualitative data synthesis of the studies. The main findings of this study are that migrants with somatization were more psychologically distressed, had an increased perceived need for healthcare service utilization, and reported more PMLD and/or PTSD than those without somatization. Specific individual features mediated the association between somatization and migration. The prevalence and correlates of somatization were found to vary across the immigrant groups, depending on cultural variation, in reasons for migration, stress exposure, explanatory models of illness, coping, and other individual variables.

In our first hypothesis, somatization would be significantly associated with migration because of the supposed high exposure to stressful experiences in individuals with migratory backgrounds. Rates of somatization in immigrants ranged between 12.9 and 67\% (Nadeem et al., 2009; Rask et al., 2016). As shown in the results reported in the collected articles, there was an extreme variability in the association between somatization and migration according to the heterogeneity of the studied migrant populations, both in terms of mental health as well as other individual variables. Being female, older, and having low language proficiency are significant sociodemographic risk factors for somatization among immigrants (Ritsner et al., 2000; Mak and Zane, 2004; Aragona et al., 2005; Bragazzi et al., 2014; Dreher et al., 2017; Morawa et al., 2017). This suggests that some sociodemographic variables may represent specific risk factors for somatization across all ethnic groups. Studies showed conflicting results when taking into account other sociodemographic variables such as length of residence (Ritsner et al., 2000; Mak and Zane, 2004; Shiroma and Alarcon, 2011;
Aragona et al., 2012), income (Mirdal, 2006; Choi et al., 2017), acculturation (Mak and Zane, 2004; Shiroma and Alarcon, 2011), education level (Mak and Zane, 2004; Shiroma and Alarcon, 2011), and marital status (Ritsner et al., 2000; Aragona et al., 2008). Additionally, some studies (Miranda et al., 2005; Mirdal, 2006; Nadeem et al., 2008, 2009; David et al., 2012; Mölsä et al., 2014, 2017) did not find significant differences in levels of somatization between migrants and the host country's natives; alternatively, the differences became not statistically significant after adjustment for sociodemographic confounding variables (Salinero-Fort et al., 2015). These findings could be explained by the "healthy migrant" effect (Razum et al., 2000). Several studies have suggested that recent immigrants are generally healthier than native-born populations, notwithstanding that they frequently have a lower socioeconomic status and less access to health care services. This "epidemiological paradox" is usually attributed to a self-selection process prior to migration, "cultural buffering," and official health screening and employability in receiving countries (Domnich et al., 2012). Another consideration is that the somatization disparities became not statistically significant when migrant and native populations were recruited from psychiatric (Nadeem et al., 2008, 2009), socioeconomic (Miranda et al., 2005), and clinically disadvantaged settings (Mirdal, 2006; David et al., 2012).

By contrast, somatization was found to be significantly prevalent in immigrants in only four studies that compared samples of immigrants with the host country's natives (Beirens and Fontaine, 2011; Deisenhammer et al., 2012; Bragazzi et al., 2014; Dreher et al., 2017). Among these, only two studies (Beirens and Fontaine, 2011; Deisenhammer et al., 2012) tried to clarify the independent relationship between migration and somatization, by comparing individuals of the same nationality with and without migratory backgrounds. Contrary to expectations, results showed that levels of somatization in migrants were not significantly higher than those reported by non-migrant individuals with the same nationality. These results could be explained by the "health selection hypothesis." This construct suggests that immigrants tend to be different from their compatriots who do not migrate (Chiquiar and Hanson, 2002; Chiswick et al., 2008). Thus, immigrants may be more educated, less risk exposed, more entrepreneurial and better prepared to confront stressful situations (Anderson et al., 2004). Instead, some studies (Small et al., 2003; Karasz et al., 2007; Aragona et al., 2008, 2011; Sachs et al., 2008; Schweitzer et al., 2011; Shiroma and Alarcon, 2011; Deisenhammer et al., 2012; Rask et al., 2015, 2016) have underscored that the impact of life events, sociodemographic and clinical features, and the prevalence of somatization and its symptomatology varied between different ethnic groups. For example, in three multicultural studies (Aragona et al., 2005, 2008, 2012), the likelihood of somatization varied widely among the different groups and was significantly higher in Latin Americans. These results suggest that the relationship between somatization and migration is particularly complex and culturally mediated; hence, any diagnosis or treatment of the individual with migratory background must be grounded in some knowledge of the person's ethnic origin. Postulating the existence of such an 
intimate and harmonious connection between somatization and ethnicity, however, overlooks a pivotal distinction: while it is true that ethnic variations can and do affect psychopathological presentations, some pathogenic features are so overwhelming that they will be expressed in any environment.

In our second hypothesis, the prevalence and correlates of somatization would be different, based on cultural variation in reasons for migration, trauma exposure, coping, and explanatory models of illness across immigrant groups and receiving contexts. Most of the examined papers (Hondius et al., 2000; Sachs et al., 2008; Aragona et al., 2010, 2011, 2013; Stewart et al., 2012; Choi et al., 2017; Mölsä et al., 2017) reported that immigrants use somatization to express their distress associated with premigration (e.g., material deprivation, religious persecution, torture, sexual abuse, being forced to harm others, loss of loved ones) and to post-migration (e.g., difficulties in accessing health and welfare services, difficulties in finding work or bad job conditions, stressors linked to the acculturation process, poverty, and discrimination) adverse life events. Pre-migratory traumatic events may have ongoing indirect effects by increasing the vulnerability of immigrants to future stressors, thus leading to more frequent PMLD. The presence and amount of PMLD are positively correlated with somatization (Aragona et al., 2011; Schweitzer et al., 2011). Moreover, PMLD in somatizers may exacerbate an existing predisposition to PTSD caused by exposure to pre-migration trauma (Schweitzer et al., 2011). This relation between pre-migratory traumas, PTSD, PMLD, and overall psychopathological symptoms is relevant because it stresses that traumatic experiences are key factors in immigrant psychopathology. Patients attribute their symptoms to past traumatic experiences and believe that PMLD contributes to their chronicity (Perron and Hudelson, 2006; Whitley et al., 2006). As a result, they formulate their suffering in both medical and social or legal terms, seeking help from physicians for all of them (Perron and Hudelson, 2006). Somatization increases the perceived need for care and health care service utilization (Nadeem et al., 2009). Moreover, increased rates of medical service utilization (especially family doctors) and increased utilization of non-medical services (i.e., traditional healers, religious leaders) were found to be strongly associated with somatization in immigrants (Ritsner et al., 2000; Fenta et al., 2006; Nadeem et al., 2008). Although somatizing immigrants tend to present high levels of help-seeking behaviors (Ritsner et al., 2000) and social interactions generally appear to play an important role in mental health and wellness for immigrants (Ahn et al., 2017), studies have shown that perceived social support did not affect somatization when post-migration stress (Mendoza et al., 2017) or traumatic experiences (Stewart et al., 2012) occur.

Studies have suggested that immigrants all over the world experience significantly more stressful life events, negative emotions, and psychological distress than non-immigrants, and therefore have a higher risk of somatization (Buchwald et al., 1986; Castillo et al., 1995). The tendency to somatize emotional distress was associated with poor mental health and quality of life in migrant populations (Mirdal, 2006; Rask et al., 2015, 2016; Choi et al., 2017). Studies have also found a comorbidity between severe depression and somatization (Mak and Zane, 2004; Borra, 2011; Heredia Montesinos et al., 2012; Morawa et al., 2017). Moreover, research has shown that the tendency to report physical complaints could be an expression of overall psychological distress and depressive symptoms in immigrants (Borra, 2011; Deisenhammer et al., 2012; Heredia Montesinos et al., 2012).

However, negative emotions seem to be associated with somatization, independent of the migration factor (Beirens and Fontaine, 2011). The explanatory models of illness episodes may differ sharply among different cultural groups, yet psychological attribution is rarely accepted; instead, individuals tend to communicate distress through concrete expressions about the body (Bäärnhielm and Ekblad, 2000; Karasz et al., 2007). From this perspective, somatization may not necessarily be a pathological mechanism among migrant populations, but rather a product of cultural differences.

Caution, however, should be exercised when interpreting the findings of this systematic review because of the limits of the reviewed studies. Overall, studies prevalently adopted a crosssectional design $(n=38)$, used only one method for assessing somatization (Ritsner et al., 2000; Small et al., 2003; Mak and Zane, 2004; Heredia Montesinos et al., 2012; Bragazzi et al., 2014), and are difficult to compare because different definitions for somatization were applied. Different somatization measures were used, with different cutoff points for somatization. In addition, most studies did not look at coexisting somatic disorders; a thorough somatic examination was rarely included. Thus, in most cases, a full diagnosis of the somatic symptom disorder could not be reached. Moreover, 29 studies used self-report questionnaires to evaluate somatization; among these, seven (Mak and Zane, 2004; Cwikel et al., 2008; Heredia Montesinos et al., 2012; Mölsä et al., 2014, 2017; Rask et al., 2015, 2016) did not specify in which language the scales were administered or whether the scales were adapted to the language of the participants. Therefore, it would be advisable for future studies to use the same instruments, with consistent cutoff points for somatization. When translated, there should be a backtranslation, and after that a validation of the questionnaire.

During our examination of the environmental factors related to health in immigrants, it became clear that there was a lack of tailored therapies that included psychological, social, and legal assistance with the aim of promoting adjustment and acculturation, improving mental health, and mitigating the symptoms of somatization in immigrant patients. Indeed, only two studies sought to evaluate the effects of treatment interventions on somatization in immigrants (Nickel et al., 2006; Van Wyk et al., 2012). In addition, as patients and health care professionals face differences in cultural backgrounds (e.g., linguistic barriers, variant health/illness beliefs, different medical practices, lack of knowledge about health care systems), understanding and treating somatization in multicultural settings is particularly challenging (Perron and Hudelson, 2006; Bäärnhielm, 2012; Dastjerdi, 2012). Based on the available literature, there is a clear need for better access to healthcare services for immigrants that is both culturally and linguistically appropriate and, as well, affordable for low-income 
individuals (Radl-Karimi et al., 2018). Clinically, depending on the country of origin, health care professionals should be aware of the immigrant patients' tendency to somatize psychological distress and of their ascriptions of meaning of symptoms within a multicultural milieu. Pre-migration, migration, and postmigration experiences all include risk factors for mental health. In this regard, the complexity of both the migratory phenomenon and acculturative stress, with their potentially traumatic burden, should be considered.

The present review supports the need to determine the psychological processes and socioeconomic factors that may increase the tendency to somatize in individuals with migratory backgrounds. From a clinical perspective, it seems essential to identify those subgroups at higher somatization

\section{REFERENCES}

Ahn, J. A., Kim, T., Roh, E. H., and Song, J. E. (2017). Health of international marriage immigrants women in South Korea: a systematic review. J. Immigr. Minor. Health 20, 717-728. doi: 10.1007/s10903-017-0604-6

Alexander, F. (1950). Psychosomatic Medicine. New York, NY: Norton.

American Psychiatric Association (1994). Diagnostic and Statistical Manual of Mental Disorders (DSM-IV), 4th Edn. Washington, DC: American Psychiatric Association.

American Psychiatric Association (2013). Diagnostic and Statistical Manual of Mental Disorders (DSM-5), 5th Edn. Arlington, VA: American Psychiatric Publishing.

Anderson, N. B., Bulatao, R. A., and Cohen, B. (2004). Critical Perspectives on Racial and Ethnic Differences in Health in Late Life. Washington, DC: National Academies Press.

Aragona, M., Catino, E., Pucci, D., Carrer, S., Colosimo, F., Lafuente, M., et al. (2010). The relationship between somatization and posttraumatic symptoms among immigrants receiving primary care services. J. Trauma. Stress 23, 615-622. doi: 10.1002/jts.20571

Aragona, M., Monteduro, M. D., Colosimo, F., Maisano, B., and Geraci, S. (2008). Effect of gender and marital status on somatization symptoms of immigrants from various ethnic groups attending a primary care service. Ger. J. Psychiatr. $11,64-72$.

Aragona, M., Pucci, D., Carrer, S., Catino, E., Tomaselli, A., Colosimo, F., et al. (2011). The role of post-migration living difficulties on somatization among first-generation immigrants visited in a primary care service. Ann. Ist. Super. Sanità 47, 207-213. doi: 10.4415/ANN_11_02_13

Aragona, M., Pucci, D., Mazzetti, M., Maisano, B., and Geraci, S. (2013). Traumatic events, post-migration living difficulties and post-traumatic symptoms in first generation immigrants: a primary care study. Ann. Ist. Super. Sanità 49, 169-175. doi: 10.4415/ANN_13_02_08

Aragona, M., Rovetta, E., Pucci, D., Spoto, J., and Villa, A. M. (2012). Somatization in a primary care service for immigrants. Ethn. Health 17, 477-491. doi: 10.1080/13557858.2012.661406

Aragona, M., Tarsitani, L., Colosimo, F., Martinelli, B., Raad, H., Maisano, B., et al. (2005). Somatization in primary care: a comparative survey of immigrants from various ethnic groups in Rome, Italy. Int. J. Psychiatry Med. 35, 241-248. doi: 10.2190/2G8N-MNNE-PGGP-PJJQ

Bäärnhielm, S. (2012). The meaning of pain: a cultural formulation of a Syrian woman in Sweden. Transcult. Psychiatry 49, 105-120. doi: $10.1177 / 1363461511427781$

Bäärnhielm, S., and Ekblad, S. (2000). Turkish migrant women encountering health care in Stockholm: a qualitative study of somatization and illness meaning. Cult. Med. Psychiatry 24, 431-452. doi: 10.1023/A:100567 1732703

Barsky, A. J., and Klerman, G. L. (1983). Overview: hypochondriasis, bodily complaints, and somatic styles. Am. J. Psychiatry. 140, 273- 283. doi: 10.1176/ajp.140.3.273 risk through their social and psychological characteristics. Clinical management should include efforts to address inherent emotional distress, as may be generated through their migratory experience. Further, special attention should be paid to the social, cultural and linguistic issues that can pose additional obstacles in the assessment and treatment phases and in the development of a therapeutic alliance with the patient.

\section{AUTHOR CONTRIBUTIONS}

All authors participated in the concept and writing of this manuscript. All authors approved the final version of the manuscript.

Beirens, K., and Fontaine, J. R. J. (2011). Somatic complaint differences between Turkish immigrants and Belgians: do all roads lead to Rome? Ethn. Health 16, 73-88. doi: 10.1080/13557858.2010.529113

Bermejo, I., Mayninger, E., Kriston, L., and Härter, M. (2010). [Mental disorders in people with migration background compared with German general population]. Psychiatr. Prax. 37, 225-232. doi: 10.1055/s-0029-1223513

Borra, R. (2011). Depressive disorder among Turkish women in the Netherlands: a qualitative study of idioms of distress. Transcult. Psychiatry 48, 660-674. doi: $10.1177 / 1363461511418395$

Bragazzi, N. L., Del Puente, G., and Natta, W. M. (2014). Somatic perception, cultural differences and immigration: results from administration of the Modified Somatic Perception Questionnaire (MSPQ) to a sample of immigrants. Psychol. Res. Behav. Manag. 7, 161-166. doi: 10.2147/PRBM.S55393

Breuer, J., and Freud, S. (1893-1895). "Studies on hysteria," in Standard Edition of the Complete Psychological Works of Sigmund Freud. Vol. 2, ed J. Strachey (London: Hogarth; Trans. \& Ed.), xxix-305.

Bridges, K. W., and Goldberg, D. P. (1987). Somatic presentation of DSM-III psychiatric disorders in primary care. J. Psychosom. Res. 29, 563-569.

Buchwald, D., Manson, S. M., von Knorring, A. I., and Cloninger. C. R. (1986). Symptom patterns and causes of somatization in men: differentiation of two discrete disorders. Genet. Epidemiol. 3, 153-169. doi: 10.1002/gepi.1370030303

Carta, M. G., Bernal, M., Hardoy, M. C., and Haro-Abad, J. M. (2005). Report on the mental health in europe working group. Clin. Pract. Epidemiol. Ment. Health. 1:13. doi: 10.1186/1745-0179-1-13

Castillo, R., Waitzkin, H., Ramirez, Y., and Escobar, J. I. (1995). Somatization in primary care, with a focus on immigrants and refugees. Arch. Fam. Med. 4, 637-646. doi: 10.1001/archfami.4.7.637

Chiquiar, D., and Hanson, G. (2002). International Migration, Self-Selection, and the Distribution of Wages: Evidence From Mexico and the United States. Cambridge MA: NBER.

Chiswick, B. R., Lee, Y. L., and Miller, P. W. (2008). Immigration selection systems and immigrants health. Contemp. Econ. Policy. 26, 555-578. doi: 10.1111/j.1465-7287.2008.00099.x

Choi, Y., Lim, S. Y., Jun, J. Y., Lee, S. H., Yoo, S. Y., Kim, S., et al. (2017). The effect of traumatic experiences and psychiatric symptoms on the life satisfaction of North Korean refugees. Psychopathology 50, 203-210. doi: 10.1159/000468544

Cwikel, J., Zilber, N., Feinson, M., and Lerner, Y. (2008). Prevalence and risk factors of threshold and sub-threshold psychiatric disorders in primary care. Soc. Psychiatry Psychiatr. Epidemiol. 43, 184-191. doi: 10.1007/s00127-007-0286-9

Dastjerdi, M. (2012). The case of Iranian immigrants in the greater Toronto area: a qualitative study. Int. J. Equity Health 11:9. doi: 10.1186/1475-9276-11-9

David, M., Borde, T., and Siedentopf, F. (2012). Do immigration and acculturation have an impact on hyperemesis gravidarum? Results of a study in Berlin/Germany. J. Psychosom. Obstet. Gynaecol. 33, 78-84. doi: 10.3109/0167482X.2012.666594

Deisenhammer, E. A., Çoban-Başaran, M., Mantar, A., Prunnlechner, R., Kemmler, G., Alkin, T., et al. (2012). Ethnic and migrational impact on the 
clinical manifestation of depression. Soc. Psychiatry Psychiatr. Epidemiol. 47, 1121-1129. doi: 10.1007/s00127-011-0417-1

Derogatis, L. R. (1977). SCL-90-R: Administration, Scoring and Procedure Manual I. Baltimore, MD: John Hopkins.

Derogatis, L. R., Lipman, R. S., Rickels, K., Uhlenhuth, E. H., and Covi, L. (1974). The Hopkins Symptom Checklist (HSCL): a self-report symptom inventory. Behav. Sci. 19, 1-15. doi: 10.1002/bs.3830190102

Derogatis, L. R., and Spencer, R. M. (1982). The Brief Symptom Inventory (BSI): Administration, Scoring and Procedures Manual I. Baltimore, MD: John Hopkins University School of Medicine.

Domnich, A., Panatto, D., Gasparini, R., and Amicizia, D. (2012). The "healthy immigrant" effect: does it exist in Europe today? Ital. J. Public Health 9:e7532. doi: $10.2427 / 7532$

Dreher, A., Hahna, E., Diefenbachera, A., Nguyenb, M. H., Bögeb, K., Buriana, H., et al. (2017). Cultural differences in symptom representation for depression and somatization measured by the PHQ between Vietnamese and German psychiatric outpatients. J. Psychosom. Res. 102, 71-77. doi: 10.1016/j.jpsychores.2017.09.010

Escobar, J. I. (1995). Transcultural aspects of dissociative and somatoform sisorders. Psychiatr Clin. North Am. 18, 555-569. doi: 10.1016/S0193-953X(18)30040-6

Escobar, J. L., Ribio-Stipec, M., Canino, G., and Karno, M. (1989). Somatic Symptom Index (SSI): a new and abridged somatization construct. J. Nerv. Ment. Dis. 177, 140-146. doi: 10.1097/00005053-198903000-00003

Fenta, H., Hyman, I., and Noh, S. (2006). Mental health service utilization by Ethiopian immigrants and refugees in Toronto. J. Nerv. Ment. Dis. 194, 925-934. doi: 10.1097/01.nmd.0000249109.71776.58

First, M. B., Spitzer, R. L., Gibbon, M., and Williams, J. B. W. (1997). Structured Clinical Interview for DSM-IV Axis I disorders (SCID I). New York, NY: Biometric Research Department.

Groleau, D., and Kirmayer, L. J. (2004). Sociosomatic theory in Vietnamese immigrants' narratives of distress. Anthropol. Med. 11, 117-133. doi: 10.1080/13648470410001678631

Gureje, O., Simon, G. E., Ustun, T. B., and Goldberg, D. P. (1997). Somatization in cross-cultural perspective: a World Health Organization study in primary care. Am. J. Psychiatry 154, 989-995. doi: 10.1176/ajp.154.7.989

Haller, H., Cramer, H., Lauche, R., and Dobos, G. (2015). Somatoform disorders and medically unexplained symptoms in primary care: a systematic review and meta-analysis of prevalence. Dtsch. Ärztebl. Int. 112, 279-287. doi: 10.3238/arztebl.2015.0279

Heredia Montesinos, A., Rapp, M. A., Temur-Erman, S., Heinz, A., Hegerl, U., and Schouler-Ocak, M. (2012). The influence of stigma on depression, overall psychological distress, and somatization among female Turkish migrants. Eur. Psychiatry. 27, S22-S26. doi: 10.1016/S0924-9338(12)75704-8

Hondius, A. J. K., van Willigen, L. H. M., Kleijn, W. C., and van der Ploeg, H. M. (2000). Health problems among Latin-American and middleeastern refugees in the Netherlands: relations with violence exposure and ongoing sociopsychological strain. J. Trauma. Stress 13, 619-634. doi: 10.1023/A:1007858116390

Jackson, J. L., and Kroenke, K. (2008). Prevalence, impact, and prognosis of multisomatoform disorder in primary care: a 5-year follow-up study. Psychosom. Med. 70, 430-434. doi: 10.1097/PSY.0b013e31816aa0ee

Karasz, A., Dempsey, K., and Fallek, R. (2007). Cultural differences in the experience of everyday symptoms: a comparative study of South Asian and European American women. Cult. Med. Psychiatry 31, 473-497. doi: 10.1007/s11013-007-9066-y

Kirmayer, L. J., and Sartorius, N. (2007). Cultural models and somatic syndromes. Psychosom. Med. 69, 832-840. doi: 10.1097/PSY.0b013e31815b002c

Kirmayer, L. J., and Young, A. (1998). Culture and somatization: clinical, epidemiological, and ethnographic perspectives. Psychosom. Med. 60, 420-430. doi: 10.1097/00006842-199807000-00006

Liberati, A., Altman, D. G., Tetzlaff, J., Mulrow, C., Gotzsche, P. C., Ioannidis, J. P., et al. (2009). The PRISMA statement for reporting systematic reviews and meta-analyses of studies that evaluate health care interventions: explanation and elaboration. BMJ 339:2700b. doi: 10.1136/bmj.b2700

Lipowski, Z. J. (1988). Somatization: the concept and its clinical application. Am. J. Psychiatry 145, 1358-1368. doi: 10.1176/ajp.145.11.1358
Mai, F. M., and Merkey, H. (1980). Briquet treatise on hysteria: a synopsis and commentary. Arch Gen Psychiatry. 37, 1401-1405. doi: 10.1001/archpsyc. 1980.01780250087010

Main, C. J. (1983). The Modified Somatic Perception Questionnaire MSPQ. J. Psychosom. Res. 27, 503-514. doi: 10.1016/0022-3999(83)90040-5

Mak, W. W. S., and Zane, N. W. S. (2004). The phenomenon of somatization among community Chinese Americans. Soc. Psychiatry Psychiatr. Epidemiol. 39, 967-974. doi: 10.1007/s00127-004-0827-4

Mendoza, N. B., Mordenoc, I. G., Latkinb, C. A., and Hall, B. J. (2017). Evidence of the paradoxical effect of social network support: a study among Filipino domestic workers in China. Psychiatry Res. 255, 263-271. doi: 10.1016/j.psychres.2017.05.037

Miranda, J., Siddique, J., Belin, T. R., and Kohn-Wood, L. P. (2005). Depression prevalence in disadvantaged young black women-African and Caribbean immigrants compared to US-born African Americans. Soc. Psychiatry Psychiatr. Epidemiol. 40, 253-258. doi: 10.1007/s00127-005-0879-0

Mirdal, G. M. (2006). Stress and distress in migration: twenty years after. IMR 40, 375-389. doi: 10.1111/j.1747-7379.2006.00021.x

Mölsä, M., Punamäki, R.-L., Saarni, S. I., Tiilikainen, M., Kuittinen, S., and Honkasalo, M.-L. (2014). Mental and somatic health and pre- and postmigration factors among older Somali refugees in Finland. Transcult. Psychiatry 51, 499-525. doi: 10.1177/1363461514526630

Mölsä, M., Tiilikainen, M., and Punamäki, R.-L. (2017). Usage of healthcare services and preference for mental healthcare among older Somali immigrants in Finland. Ethn. Health 3, 1-16. doi: 10.1080/13557858.2017.1346182

Morawa, E., Draganob, N., Jöckel, K-H., Moebus, S., Brandd, T., and Erim, Y. (2017). Somatization among persons with Turkish origin: results of the pretest of the German National Cohort Study. J. Psychosom. Res. 96, 1-9. doi: 10.1016/j.jpsychores.2017.02.014

Mumford, D. B., Bavington, J. T., Bhatnagar, K. S., Hussain, Y., Mirza, S., and Naraghi, M. M. (1991). The Bradford Somatic Inventory. a multi-ethnic inventory of somatic symptoms reported by anxious and depressed patients in Britain and the Indo-Pakistan subcontinent. Br. J. Psychiatry. 158, 379-86.

Nadeem, E., Lange, J. M., and Miranda, J. (2008). Mental health care preferences among low-income and minority women. Arch. Womens Ment. Health 11, 93-102. doi: 10.1007/s00737-008-0002-0

Nadeem, E., Lange, J. M., and Miranda, J. (2009). Perceived need for care among low-income immigrant and U.S.-born black and Latina women with depression. J. Womens Health 18, 369-375. doi: 10.1089/jwh.2008.0898

Nickel, M., Cangoez, B., Bachler, E., Muehlbacher, M., Lojewski, N., MuellerRabe, N., et al. (2006). Bioenergetic exercises in inpatient treatment of Turkish immigrants with chronic somatoform disorders: a randomized, controlled study. J. Psychosom. Res. 61, 507-513. doi: 10.1016/j.jpsychores.2006.01.004

Perron, N. J., and Hudelson, P. (2006). Somatisation: illness perspectives of asylum seeker and refugee patients from the former country of Yugoslavia. BMC Fam. Pract. 7:10. doi: 10.1186/1471-2296-7-10

Perruchoud, R. (2004). Glossary on Migration. Geneva: International Organization for Migration (IOM).

Perruchoud, R., and Redpath-Cross, J. (2011). Glossary on Migration. Book Glossary on Migration. Geneva: International Organization for Migration (IOM).

Radl-Karimi, C., Nicolaisen, A., Sodemann, M., Batalden, P., and von Plessen, C. (2018). Coproduction of healthcare service with immigrant patients: protocol of a scoping review. BMJ 8:e019519. doi: 10.1136/bmjopen-2017-019519

Rask, S., Castaneda, A. E., Koponen, P., Sainio, P., Stenholm, S., Suvisaari, J., et al. (2015). The association between mental health symptoms and mobility limitation among Russian, Somali and Kurdish migrants: a population based study. BMC Public Health 15:275. doi: 10.1186/s12889-015-1629-1

Rask, S., Suvisaari, J., Koskinen, S., Koponen, P., Mölsä, M., Lehtisalo, R., et al. (2016). The ethnic gap in mental health: a population-based study of Russian, Somali and Kurdish origin migrants in Finland. Scand. J. Public Health 44, 281-290. doi: 10.1177/1403494815619256

Razum, O., Zeeb, H., and Rohrmann, S. (2000). The 'healthy migrant effect'not merely a fallacy of inaccurate denominator figures. Int. J. Epidemiol. 29, 191-192. doi: 10.1093/ije/29.1.191

Rief, W., Hiller, W., and Heuser, J. (1997). SOMS - The Screening for Somatoform Symptoms. Bern: Huber- Verlag. 
Ritsner, M., Ponizovsky, A., Kurs, R., and Modai, I. (2000). Somatization in an immigrant population in Israel: a community survey of prevalence, risk factors, and help-seeking behavior. Am. J. Psychiatry 157, 385-392. doi: 10.1176/appi.ajp.157.3.385

Rohlof, H. G., Knipscheer, J. W., and Kleber, R. J. (2014). Somatization in refugees: a review. Soc. psychiatry Psychiatr. Epidemiol. 49, 1793-1804. doi: 10.1007/s00127-014-0877-1

Sachs, E., Rosenfeld, B., Lhewa, D., Rasmussen, A., and Keller, A. (2008). Entering exile: trauma, mental health, and coping among Tibetan refugees arriving in Dharamsala, India. J. Trauma. Stress 21, 199-208. doi: 10.1002/jts.20324

Salinero-Fort, M. A., Jimenez-Garcia, R., de Burgos-Lunar, C., Chico-Moraleja, R. M., and Gomez-Campelo, P. (2015). Common mental disorders in primary health care: differences between Latin American-born and Spanish-born residents in Madrid, Spain. Soc. Psychiatry Psychiatr. Epidemiol. 50, 429-443. doi: 10.1007/s00127-014-0962-5

Schweitzer, R. D., Brough, M., Vromans, L., and Asic-Kobe, M. (2011). Mental health of newly arrived Burmese refugees in Australia: contributions of premigration and post-migration experience. Aust. N. Z. J. Psychiatry. 45, 299-307. doi: 10.3109/00048674.2010.543412

Shiroma, P. R., and Alarcon, R. D. (2011). Time for healing: somatization among chronically mentally ill immigrants. J. Cult. Divers. 18, 3-7.

Silove, D., Steel, Z., McGorry, P., and Mohan, P. (1998). Trauma exposure, postmigration stressors, and symptoms of anxiety, depression and post-traumatic stress in Tamil asylum-seekers: comparison with refugees and immigrants. Acta Psychiatr. Scand. 97,175-181. doi: 10.1111/j.1600-0447.1998.tb09984.x

Simon, G. E., VonKorff, M., Piccinelli, M., Fullerton, C., and Ormel, J. (1999). An international study of the relation between somatic symptoms and depression. N. Engl. J. Med. 341, 1329-1335. doi: 10.1056/NEJM199910283411801

Small, R., Lumley, J., and Yelland, J. (2003). How useful is the concept of somatization in cross-cultural studies of maternal depression? A contribution from the Mothers in a New Country (MINC) study. J. Psychosom. Obstet. Gynaecol. 24, 45-52. doi: 10.3109/01674820309042800

Spiller, T. R., Schick, M., Schnyder, U., Bryant, R. A., Nickerson, A., and Morina, N. (2016). Somatisation and anger are associated with symptom severity of posttraumatic stress disorder in severely traumatised refugees and asylum seekers. Swiss Med. Wkly. 146:w14311. doi: 10.4414/smw.2016.14311

Spitzer, R.L.,Williams, J. B., Kroenke, K., Linzer, M., deGruy, F. V. 3rd., Hahn, S. R., et al. (1994). Utility of a new procedure for diagnosing mental disorders in primary care: the PRIME-MD 1000 study. JAMA 272, 1749-1756 doi: 10.1001/jama.1994.03520220043029

Stewart, D. E., Gagnon, A. J., Merry, L. A., and Dennis, C.-L. (2012). Risk factors and health profiles of recent migrant women who experienced violence associated with pregnancy. J. Womens Health 21, 1100-1106. doi: 10.1089/jwh.2011.3415

Swartz, M., Hughes, D., George, L., Blazer, D., Landerman, R., and Bucholz, K. (1986). Developing screening index for community studies of somatization disorder. J. Psychiatr. Res. 20, 335-343. doi: 10.1016/0022-3956(86)9 0036-1

United Nations Population Division Department of Economic and Social Affairs (2009). Trends in International Migrant Stock: The 2008 Revision. United Nations Database. POP/DB/MIG/Stock/Rev. 2008.

United Nations Population Division Department of Economic and Social Affairs (2017). Trends in International Migrant Stock: The 2017 Revision. United Nations Database. POP/DB/MIG/Stock/Rev.2017.

Van Wyk, S., Schweitzer, R., Brough, M., Vromans, L., and Murray, K. (2012). A longitudinal study of mental health in refugees from Burma: the impact of therapeutic interventions. Aust. N. Z. J. Psychiatry. 46, 995-1003. doi: $10.1177 / 0004867412443059$

Ware, J., and Sherbourne, C. (1992). The MOS 36-item short-form health survey (SF-36): I. Conceptual Framework and Item Selection. Med. Care. 30, 473-483. doi: 10.1097/00005650-199206000-00002

Whitley, R., Kirmayer, L. J., and Groleau, D. (2006). Public pressure, private protest: illness narratives of west indian immigrants in montreal with medically unexplained symptoms. Anthropol. Med. 13, 193-205. doi: $10.1080 / 13648470600863548$

Conflict of Interest Statement: The authors declare that the research was conducted in the absence of any commercial or financial relationships that could be construed as a potential conflict of interest.

Copyright (c) 2019 Lanzara, Scipioni and Conti. This is an open-access article distributed under the terms of the Creative Commons Attribution License (CC BY). The use, distribution or reproduction in other forums is permitted, provided the original author(s) and the copyright owner(s) are credited and that the original publication in this journal is cited, in accordance with accepted academic practice. No use, distribution or reproduction is permitted which does not comply with these terms. 